\title{
Validation of the climatic zoning defined by ASHRAE Standard 169-2013
}

\author{
Angélica Walsh ${ }^{1}$, Daniel Cóstola ${ }^{2}$, Lucila Chebel Labaki ${ }^{1}$ \\ 1 - UNICAMP State University of Campinas, Brazil \\ 2 -University of Strathclyde, Scotland, United Kingdom
}

\begin{abstract}
Climatic zoning has a direct impact on building energy efficiency policies. Currently, most countries adopt simplified weather parameters to define their climatic zoning, with the degree-days method being the most widely used. This widespread use of degree-days has been substantially influenced by the adoption of this indicator by ASHRAE on its climatic zoning, which is a core element for the prescription of requirements for buildings based on their location. However, there is no scientific evidence regarding the agreement between building energy performance and the ASHRAE climatic zones. The objective here was to quantify the mismatch between buildings' energy performance in each given location and the expected energy performance in the climatic zone they are placed. The study uses a performance-based assessment method relying on building energy simulation and GIS. Climatic zoning performance indicators were calculated based on the energy demand of 52 archetype buildings of the U.S. building stock complying with the ASHRAE Standard 90.1-2013. EnergyPlusV8.3 and ArcGIS were used in the process. Results suggest that the stipulated climatic zone misclassifies $10 \%$ of the area evaluated, potentially misclassifying highly populated urban areas. These misclassifications have direct impact on the building energy efficiency policies of a given location, which may not be the most adequate for its climate.
\end{abstract}

Keywords: Climatic zoning, building energy performance, degree-days.

A peer reviewed, accepted author manuscript of the following research article: Walsh, A., Cóstola, D., \& Labaki, L. (2019). Validation of the climatic zoning defined by ASHRAE standard 169-2013. Energy Policy, 135, [111016]. 


\section{INTRODUCTION}

Climatic zoning for building energy efficiency applications is an important element in building energy policy, as many standards, certifications, and regulations rely on this approach (Walsh et al., 2017a). This can be exemplified by regulations implemented or under consideration in many countries, such as Brazil (Bavaresco et al., 2017; Fossati et al., 2016), China (Hong et al., 2015; Hu et al., 2016), Italy (Costanzo et al., 2016; Italian Legislative Decree n. 192/05, 2005), Greece (Dascalaki et al., 2012), Turkey (Sisman et al., 2007), and the United States of America (ANSI/ASHRAE, 2013a). These regulations are key instruments used to enforce minimum performance targets, to define subsidies and to implement strategies to achieve ambitious goals for energy conservation and $\mathrm{CO}_{2}$ emission reductions. Despite the relevance, most of the current climatic zonings methodologies are based on simplified weather parameters and are usually assumed to be correct and valid per se, being directly applied to building energy regulations without going through a validation process (Walsh et al., 2018a). These assumptions can lead to inconsistencies between the climatic zones and energy performance of individual buildings, consequently affecting the performance of the whole building stock and the effectiveness of building energy policies (Burleyson et al., 2017; M. Carpio et al., 2015; Pusat and Ekmekci, 2016).

An extensive review of climatic zoning methods was recently published, covering 54 countries responsible of $85 \%$ of the total primary energy consumption, representing $70 \%$ of the world land surface and hosting $71 \%$ of the world population (Walsh et al., 2017a). Results of this review suggest that the degree-days method is the most commonly used indicator for climate zoning, being adopted in $38 \%$ of the cases. Degree-days are defined as the difference in temperature between the outdoor mean air temperature over a 24-hour period and a given base temperature (ANSI/ASHRAE, 2013b). It has the advantage of being simple to calculate as it is based on a single parameter, however building energy efficiency is influenced by several weather parameters (Clarke, 2001) which may reduce the validity of the degree-day method. Although less common than the degree-days method, building energy simulation (BES) is becoming more widely used in climatic zoning applications (Praene et al., 2019; Verichev and Carpio, 2019). It has been adopted in $8 \%$ of cases covered in the review. BES is considered the most accurate method to predict thermal building performance nowadays, and it has shown a great potential as a tool for policy making (Drury Browne Crawley, 2008). However there are some constraints for its application in the climatic zoning process, such as the need to predefine a design hypothesis which varies according to architectural typology, occupational patterns, systems and building control. In addition, there is a need for detailed climatic data, which are not always available for the regions of interest. Another method identified in the review is the Cluster analysis, which is a multivariate pattern recognition technique for data classification and segmentation (Jain, 2010), present in $6 \%$ of the cases. It allows investigating climate data under various aspects 
simultaneously for a wide range of research questions. However judgment must be used in many stages of cluster analysis, as results are sensitive to assumptions regarding the cluster algorithm, input variables, and number of clusters. Givoni bioclimatic chart (GBC) has been adopted in 5\% of the cases. GBC is a pre-design bioclimatic tool that correlates passive design strategies with external air temperatures and relative humidity using a custom psychrometric chart (Lomas et al., 2004). This tool is simple to use, however, it disregards some climatic variables that influence thermal behaviour of buildings, such as solar radiation and wind exposure (Lomas et al., 2004). Mahoney tables are used in a few cases covered in the review (3\%). The main advantages of Mahoney tables are the simplicity and low input requirements (Koenigsberger et al., 1971). Predominant climatic features are identified using Mahoney tables, and consequently, the corresponding passive design solution. However, it is not meant to support detailed prescriptive-based or performance-based recommendations. A recent comparison showed significant discrepancies in zoning outcomes when different methods are adopted (Walsh et al., 2017b). There is currently no study indicating which is the most accurate to support climatic zoning for building energy policy.

Assessing the accuracy of climatic zoning methodologies is quite complex, as it involves several dynamic variables sparsely distributed in space and time (Clarke, 2018, 2001; Perez et al., 2016). Recent advancements facilitated this sort of assessment due to the use of Geographic Information Systems (GIS) and Building Energy Simulation (BES) (Clarke and Hensen, 2015; Lindberg et al., 2018; Reinhart and Cerezo Davila, 2016; SánchezLozano et al., 2013). The combination of GIS and building energy simulation enables the interpretation of performance data of a wide range of building types at a high temporal and spatial resolution (Clarke and Hensen, 2015). Besides, GIS facilitate policy making, allowing a multilayer analysis of performance data combined with other relevant information for decision making, such as population density, urban growth projections or climate change trends. Considering these potentials, researchers have developed customized solutions for policy making using BES and GIS. Examples of such solutions can be seen in the renewable energy field (Clarke et al., 2015) showing for example, opportunity maps for renewables to support informed decisions about siting community scale renewable energy systems. Other studies illustrate the potential of GIS and BES in analysing smart energy systems in the urban district scale (Nageler et al., 2017). The use of these tools have proven to be effective to handle multiple parameters and large data set simultaneously, however they do not solve the methodological challenge of using such data to perform climatic zoning validation (Walsh et al., 2017a). Rather, they provide useful functions and interoperability capabilities (Huang et al., 2017) to explore climatic zoning validation under different scenarios. 
In that regard, a method to address climatic zoning validation using quantitative procedures has been recently reported in the literature (Walsh et al., 2018a). This method is based on building performance, rather than on weather data. It relies on the principle that two areas belonging to the same climatic zoning should have similar building performance metrics for a given building. The use of the performance-based validation of climatic zoning for building energy efficiency applications has shown a great potential to quantify the level of mismatch between climatic zones and building energy performance (Walsh et al., 2018a). So far, this validation method has been applied to a case study focused on low-rise domestic buildings with no Heating, Ventilation, and Air Conditioning (HVAC) in a tropical developing country (Walsh et al., 2018a). Such results are important considering the rapid penetration of air conditioning in low income and middle income countries such as Brazil, India, China, Mexico, among other countries (Sivak, 2009; Villareal and Moreira, 2016; Wu et al., 2019). The present paper reports an application of this validation method to a range of commercial and domestic buildings with HVAC in a developed country. The validation addresses the well-established climatic zoning for the USA proposed by the American Society of Heating, Refrigerating and Air-Conditioning Engineers (ASHRAE) based on the degree-days method (ANSI/ASHRAE, 2013b).

Currently, at least 24 countries have used the degree-days approach to support their climatic zoning definition (Walsh et al., 2017a). The widespread use of degree-days in many countries has been substantially influenced by the adoption of this indicator by the ASHRAE Standards and the International Energy Conservation Code (IECC) (ANSI/ASHRAE/IES, 2013; Briggs et al., 2003; Geller et al., 2006; International Code Council, 2012). This method achieves a high correlation with HVAC energy demand in buildings and it is considered simple to calculate due to its reduced input data required (CIBSE, 2006; Jakubcionis and Carlsson, 2018; Sailor and Vasireddy, 2006). However, this simplicity come at the cost of disregarding several aspects that are important for building energy efficiency applications, e.g. solar radiation, wind and their interaction with the building envelope (Clarke, 2001; Walsh et al., 2017b; Wang et al., 2017). These variables are particularly important in hot humid climates, where ventilation, solar gains and latent loads have a large influence on building energy performance and thermal comfort, and consequently, on building energy efficiency policies (Attia et al., 2019; Rackes et al., 2016).

The original definition of the ASHRAE climatic zones was made in the context of numerous non-climatic concerns (Briggs et al., 2003). Practical considerations exerted substantial influence on the various zone boundaries. Administrative divisions designed for code compliance and the pursuit of continuity of zones were some of the drivers for the definition of boundaries between zones (Briggs et al., 2003). In the USA, these criteria 
lead to some climatic zones having clearly cohesive boundaries (no discontinuity), particularly in the north, as displayed in Figure 1(b).

At present, there is an updated version of the ASHRAE climatic zones published in the ANSI/ASHRAE Standard 169-2013, Climatic Data for Building Design Standards (ANSI/ASHRAE, 2013b). This climatic zoning is the base of the latest ASHRAE Standard 90.1-2016 (ANSI/ASHRAE/IESNA, 2016). The new climatic zoning used updated climate information (Roth, 2017), resulting in the reclassification of more than 400 counties out of a total of over 3,000 in the U.S. (when compared to the previous zoning). Most of the counties were reclassified from cooler zones to warmer zones in the U.S. These changes reflect the effect global warming in climate classification (Beck et al., 2018). This reclassification have potential impacts in the ASHRAE Standard at national level (Koirala et al., 2014), as requirements tend to be less strict in warmer zones when compared to colder zones (Athalye et al., 2016; Hogan, 2014).

Despite the updates of the climatic zones of the U.S., there are concerns about the appropriateness of the approach adopted by the ASHRAE standards, which can be exemplified by the comparison between the lowresolution USA zoning with the high-resolution zoning adopted by the State of California. This State has a climatic zoning containing 16 zones (California Energy Commission, 2017), with climate zones defined by energy use (California Energy Commission, 2013). The average area per climatic zone varies by a factor of 20 between these two climatic zoning schemes, from $2.6 \times 10^{4} \mathrm{~km}^{2}$ in California State to $5 \times 10^{5} \mathrm{~km}^{2}$ in the U.S. nationwide classification (See Figure 1). The building requirements will depend on the zoning used as a reference, which in some cases are contradictory (Ware and Bozorgchami, 2013). This lack of agreement and the impact the North American Standards have in building energy policy worldwide (Hong et al., 2015; International Code Council, 2012; Liu et al., 2010) are the key driver for the present study.

Giving that context, the aim of this study is to assess the agreement between building energy performance of a wide range of building archetypes of the U.S. building stock complying with the ASHRAE Standard 90.12013 (Deru et al., 2011; DOE, 2016), and the latest version of the ASHRAE climatic zones (ANSI/ASHRAE/IES, 2013). The assessment uses a performance-based method relying on building energy simulation and GIS (Walsh et al., 2018a). The methodology adopted in this study is described in Section 2, results are presented in Section 3, discussions in Section 4 and the conclusions and policy implications in Section 5.

\section{METHODOLOGY}

This section describes the procedure, assumptions and sample of simulations used in the performance-based validation of the ASHRAE Standard 169-2013 climatic zoning. This validation procedure consists of generating 
performance maps showing how a set of chosen indicators, such as energy consumption or thermal comfort, vary throughout the territory (country or region) for given archetype buildings, for a typical year of climatic data (Walsh et al., 2018a). These maps can be produced using building performance simulations, addressing each relevant archetype in the building stock and adopting climate files for various locations in the territory. The building performance is then linked to each climatic zone under study and areas with conflicting performance results are identified, leading to the calculation of the Percentage Misclassified Areas (PMA) which indicates in a single number the overall agreement between the building performance of a single archetype building (using a given performance indicator) and the climatic zoning.

A detailed description of the PMA calculation is provided by Walsh et al. (2018a). In summary, the calculation of PMA is based on the principle that in an ideal scenario, each climatic zone has a unique climate, which leads to a unique performance for a particular archetype. By this, minimum overlap should be observed in the building performance of an identical archetype building placed in different zones. In cases where a given area in a particular zone shows building performance that is more commonly find in another zone (and that differs from the typical performance in the zone itself), this area is considered misclassified. The percentage of misclassified areas is calculated for each building archetype and performance indicator; these results are aggregated in the Mean Percentage of Misclassified Area (MPMA) which is the average of all PMAs. The MPMA is, at the moment, the only available method to assess the quality of a given climatic zoning (Walsh et al., 2018a). It is therefore the key quality index adopted in this study to support the validation of climatic zoning results.

The following sections describe the area covered in this study, the archetype buildings and settings adopted in the energy simulations.

\subsection{Area of study}

This study covers the States of Florida, Georgia and Tennessee (Figure 2). This region extends over four climatic zones according to the ASHRAE Standard 169-2013. From 1A (Very Hot and Humid: typical city Miami), 2A (Hot: typical city Houston), 3A (Warm - Humid: typical city Memphis) to 4A (Mild and Humid: typical city Baltimore) (ANSI/ASHRAE/IES, 2013). This area covers around $433365 \mathrm{~km}^{2}$ and hosts almost 32 million people. Some of the largest cities in the area of study are Jacksonville, Nashville, Memphis, Atlanta, Miami, Tampa, Orlando, Augusta, Columbus, and Knoxville.

\subsection{Building archetypes}

The U.S. Department of Energy (DOE) has defined 16 building types for the development of the building energy code (Deru et al., 2011; DOE, 2016), largely corresponding to a classification scheme established in the 2003 
DOE/Energy Information Administration (EIA) Commercial Building Energy Consumption Survey (CBECS) (EIA, 2003). These 16 building types represent 70-80\% of the U.S. building stock. Such building models have been used to analyse the effects of energy efficiency code updates, to develop prescriptive new construction standards, to improve retrofit design guides, to create scales for asset scoring, and to develop typical energy conservation measures, among other applications (Wang and Chen, 2014). The archetypes adopted in this study represent multi-family buildings (high-rise, mid-rise), hotels (large, small), offices (small, medium, large), restaurants (fast food, sit down), retails (standalone, strip mall), and schools (primary, secondary). The key features of these archetypes are summarised in Table 1 . The present paper adopts versions of 13 different building types complying with the ASHRAE Standard 90.1-2013 (see (Glazer, 2015)).

Each of the 13 archetypes was adapted to building energy requirements of the ASHRAE Standard 90.12013 according to the four climatic Zones 1A to 4A. Therefore, each archetype has four variations, making the total of 52 models which were developed and made available by ASHRAE 1651-RP (Glazer, 2015). The differences between the four models of each archetype are related to properties of the envelope regarding the typical climate of the zone. The insulation level for the envelope (opaque and glazing) increases in colder climates. In contrast, the Solar Heat Gain Coefficient (SHGC) allowed in hotter climates is lower. Table 2 provides an example of the differences found among the models for each climate zone of the high-rise apartment archetypes. Further details about the remaining models can be found in the Supplementary material and in Ref. (Deru et al., 2011; Glazer, 2015). Results of all the models were analysed in terms of annual heating and cooling energy demand per unit floor area $(\mathrm{kWh} /(\mathrm{m} 2 . \mathrm{yr}))$. Energy demand of fans and pumps were not included in the analysis.

\subsection{Simulations and post-processing}

Simulations were carried out considering 95 locations, with weather data provided by DOE (DOE, 2018), using Energy Plus V8.3 (DOE, 2017). Cloud-based computing (Richman et al., 2014) was used to reduce the total simulation time required for this study. Results were post-processed using ArcGIS 10.6 (ESRI, 2018). The workflow was fully automated using MATLAB (MathWorks, 2016) and Python scripts (ESRI, 2018), producing results of percentage of misclassified areas for each archetype and other performance indicators.

Quality assurance methods were applied to allow a thorough assessment of results for each archetype. This was a major concern of this study, as the number of simulations have almost reached 5000 cases (52 models run for each of the 95 climate files), and output values were multiple (heating, cooling, energy use intensity, operative temperatures). Automation included generation of a number of plots for each individual simulation, automatic generation of maps with the mean percentage of misclassified areas, histograms of frequency 
distribution, boxplots, among others. These results were individually analysed to ensure each simulation provided results within the expected behaviour of buildings under a particular climate. These checks are essential to provide some degree of confidence to simulation results and consequently to the validation of climatic zoning.

\section{RESULTS}

\subsection{Results for archetype based on requirements of Zone $1 \mathrm{~A}$}

This sub-section provides a detailed analysis of one of the building archetypes (Mid-Rise apartments complying with Zone 1A requirements) in order to exemplify the nature of the results obtained (see next sub-section 3.2 for aggregated results for all archetypes). Figure 3 illustrates the variation of cooling and heating energy demand over the area of study for this archetype. As expected, cooling requirements are 3 to 4 times higher in southern regions, while heating requirements are higher in the northern areas and close to zero in the southern ones. These patterns are highly influenced by the latitude variation which is also correlated with the differences of temperatures and solar radiation. Maximum heating and cooling in the study area are of the same order of magnitude, showing that both performance indicators are relevant for this area and archetype. Results are in line with values for the same model previously reported in the literature (Glazer, 2015). Cooling and heating performance variation is qualitatively aligned with climatic zoning boundaries based on the ASHRAE Standard 169-2013. Despite such general alignment, a closer analysis shows mismatch between the performance of this archetype and the zone boundaries, as discussed below. Figure 3 Performance-based maps of a) Cooling and b) Heating energy. Figure 4 (a) presents the histogram of cooling energy demand for this archetype considering the 95 simulated locations. Zone 1A which is the hottest zone (red bins), has the highest levels of cooling demand, while Z4A (orange bins), the coolest zone, has the lowest values. Focusing the analysis on the results for Zones $3 \mathrm{~A}$ and $4 \mathrm{~A}$, the cooling energy demand varies from around 11 to $19 \mathrm{kWh} /\left(\mathrm{m}^{2}\right.$.yr $)$ in Zone $3 \mathrm{~A}$ and from 9 to $15 \mathrm{kWh} /\left(\mathrm{m}^{2} . \mathrm{yr}\right)$ in $\mathrm{Zone} 4 \mathrm{~A}$. There is a range between 11 and $15 \mathrm{kWh} /\left(\mathrm{m}^{2} . \mathrm{yr}\right)$ where buildings located in both zones have a similar performance. The area where the same building has the same performance while belonging to a different climate zone, is the one which is considered as not accurately classified. The bars in the histogram related to the misclassified areas are highlighted in Figure 4(b), where in the case for Zone 3A locations (purple bins) the bars correspond to values lower than $13 \mathrm{kWh} /\left(\mathrm{m}^{2} . \mathrm{yr}\right)$ and Zone $4 \mathrm{~A}$ locations (orange bins) to values over $13 \mathrm{kWh} /\left(\mathrm{m}^{2} . \mathrm{yr}\right)$.

The magnitude of the overlap encountered between zones can be further appreciated in Figure 4(c), where the misclassified areas are hatched over the map. The Percentage of Misclassified Areas (PMA) in this case is 11\% of the total area under analysis, which provides the key indicator about the level of misclassification for this particular archetype in this climatic zoning (see section 3.2 for PMA data for other archetypes). Three points on 
the map were selected to further discuss the implications of misclassification in building codes requirements. Points A and B, which are correctly classified as Zone $2 \mathrm{~A}$ and $3 \mathrm{~A}$ respectively, and point $\mathrm{C}$ which is misclassified as Zone 3A. The classification of points $\mathrm{A}, \mathrm{B}$ and $\mathrm{C}$ are coherent with the degree-days values at each location, however, when looking into climatic variables other than temperature, additional climatic factors become apparent. For instance, the global solar radiation displayed in Figure 5, suggest that point A and B (placed in different zones) are closer to each other than point $\mathrm{B}$ and $\mathrm{C}$ (placed in the same zone). This difference in solar radiation affects the cooling demand, which is similar for points A and B $\left(19 \mathrm{kWh} /\left(\mathrm{m}^{2} . \mathrm{yr}\right)\right.$ and $18 \mathrm{kWh} /\left(\mathrm{m}^{2} . \mathrm{yr}\right)$ respectively) and significantly lower for point $\mathrm{C}\left(12 \mathrm{kWh} /\left(\mathrm{m}^{2} . \mathrm{yr}\right)\right)$.

Results from this study suggest that points A and B are well-placed in their zones because their performance (19 and $18 \mathrm{kWh} /\left(\mathrm{m}^{2} . \mathrm{yr}\right)$ respectively) fall within the predominant range encountered for Zone $2 \mathrm{~A}$ (18 to $\left.28 \mathrm{kWh} /\left(\mathrm{m}^{2} . \mathrm{yr}\right)\right)$ and Zone $3 \mathrm{~A}\left(13\right.$ to $\left.18 \mathrm{kWh} /\left(\mathrm{m}^{2} . \mathrm{yr}\right)\right)$ respectively. While $\mathrm{C}$, is a misclassified point because its cooling performance $\left(12 \mathrm{kWh} /\left(\mathrm{m}^{2} . \mathrm{yr}\right)\right)$ is below the predominant range of performance encountered in Zone $3 \mathrm{~A}$ (13 to $\left.18 \mathrm{kWh} /\left(\mathrm{m}^{2} . y r\right)\right)$ (Figure $\left.4 \mathrm{a}\right)$. However, following the degree-days criteria, buildings constructed in B and C should in principle comply with the same building requirements, while buildings constructed in point A should adopt different ones. The differences in requirements may lead to considerable differences in terms of building efficiency and cost (Koirala et al., 2014). Therefore, accurate definition of zone boundaries is essential to avoid misclassification of areas and the corresponding adoption of inadequate building requirements in a given area.

\subsection{Results for all archetypes and performance indicators}

The PMA was calculated for each of the 52 building archetypes and each performance indicator (Figure 6). The figure shows how different buildings react to the same climatic zoning, as each archetype has a unique sensitivity to climate. This variation in sensitivity makes the performance of some archetypes more aligned with the climatic zoning in terms of heating demand, such as the high-rise apartment buildings which show low PMA for this performance indicator while large mismatch is found in terms of cooling (high PMA). Others show opposite results, with good agreement in term of cooling and high PMA for heating (such as restaurants). In practice, it shows the challenges of adopting a single climatic zoning for a variety of building types, each with its own sensitivity to each climatic variable.

Results in Figure 6 show small variation within the 4 archetypes with the same geometry and different building properties (based on ASHRAE Standard 90.1-2013 for zones 1A to 4A). This small variation can be observed, for example, in the results in the first 4 sets of bars showing PMA for high-rise buildings, which have identical geometry and orientation, and properties as listed in Table 2. This indicates that the properties listed in 
Table 2 are less important to the PMA than the geometry, orientation, internal gains, set-points and system design adopted for each building function. This stresses the need for evaluating a set of archetypes with geometry, orientation and operation matching the actual building stock. An adequate representation of the stock in these terms is as important as the properties for the envelope, such as the ones listed in Table 2. In this sense, the results presented in this paper can be taken as an initial attempt to validate the USA climatic zoning (ASHRAE Standard 169-2013), as a wider variety of archetypes would provide a more accurate results. Nevertheless, the overall PMA trend is similar amongst the 52 archetypes (which in many cases have substantially different geometry and operation). This indicates that additional archetypes were unlikely to change the main conclusions of this study.

In Figure 6, the PMA based on cooling energy demand is very similar to the one calculated based on heating energy demand (10\% and 9.6\%), and the overall MPMA is $10 \%$. This indicates that, on average, 1 out of 10 areas are misclassified in the climatic zoning under analysis (with some degree of variation depending on the building function and envelope properties). Misclassified areas may be forced to comply with building requirements that are not adequate for the local climate and building performance. Differences in requirements are not negligible in terms of construction costs and expected impact on energy bills (Koirala et al., 2014). These misclassifications have direct impact on the building energy efficiency policies of a given location, and become more relevant when large urban agglomerations, such as Atlanta, are located in potentially misclassified areas (Figure 7). Considering midrise apartments, this level of misclassification could affect more than 60 counties and 10 million people living in the zone transition areas between the four zones considered in this study.

\section{DISCUSSION}

As already mentioned, designing a single climatic zoning addressing various building types can be challenging. Figure 8 shows examples of misclassified areas of different building types and performance indicators. These sort of outputs could be useful for policymakers targeting distinct policies for different building types. In this paper, all building simulation models comply with the Standard 90.1-2013, as they represent a basis for code development and compliance in the U.S.A. These models have some limitations (Deru et al., 2011), as addressing a large building stock is always accompanied by compromises in terms of resolution and complexity. Having said that, the development of these models took into account a number of measures for quality assurance which qualify them as a valid description of the stock for the purposes of this paper. The models were based on extensive empirical statistical data regarding the building stock and their results were subjected to comparison with benchmark data for USA buildings (Deru et al., 2011; Goel et al., 2014). Model validation is essential to the their use in works like the present one, as the quality of the climatic zoning validation results will be directly related to the adoption of 
adequate building models which are able to represent the existing and/or future building stock according to the purpose of climatic zoning.

The present work only used two performance metrics in the analysis: energy consumption for space heating and cooling. The analysis and implications of the misclassification calculated for each building could be further analysed based on other sources of data according to the interest of policy makers, such as population density, areas of urban growth, projections of constructions of new buildings of each type, local energy resources, $\mathrm{CO} 2$ emissions, among others factors. Today, this type of analysis is possible with the use of GIS and simulations tools. Together with the choice of performance indicators, the adoption of adequate climatic data plays a central role in the MPMA calculation. The nature and limitations of current weather data for simulation is has been reported in the literature (Hensen, 1999; Hensen and Lamberts, 2019). This paper is based on the assumption that DOE weather files properly reflect the current climatic conditions in the area under analysis. The impact of performance indicators and weather data in the results can be observed in Figure 9. This figure shows a comparison between the results of the present paper (red bar) and previous studies using the same methodology for MPMA calculation.

Regarding the comparison between the updated ASHRAE climatic zoning (ANSI/ASHRAE, 2013b) (red bar) and the original version (Briggs et al., 2003; Walsh et al., 2018b) (dark blue bar), the mismatch between performance and climatic zoning boundaries has been significantly reduced. This reduction could be explained by the use of updated weather data in the zoning process (Roth, 2017), which is more consistent with the weather data sets for simulations provided by DOE (DOE, 2018). Such updated data also better account for the effects of climate change, indicating the need to address this point in future studies regarding zoning and its validation. This could be achieved by the adoption of future scenarios considering projected weather files (Drury B. Crawley, 2008; Taylor et al., 2014) and robust designs buildings alternatives (Kotireddy et al., 2018). These considerations may contribute to avoid the adoption of obsolete energy efficiency policies, which is a common challenge in many countries nowadays (Jenkins et al., 2013; Visscher et al., 2016).

Figure 9 also shows a comparison with data from a previous study focused on low-rise domestic buildings with no HVAC in a tropical developing country, where MPMA was 19\% (Walsh et al., 2018a) (cyan bar in Figure 9). In this case, the performance indicator was the level of thermal comfort provided by each archetype using the adaptive comfort model according the ASHRAE standard 55 (Walsh et al., 2018a), an approach that can be used as part of building regulation aiming at reducing the penetration of HVAC in hot countries with the fastest growing population (Chen et al., 2017; de Dear and Brager, 2002; Sivak, 2009). The MPMA value based on these buildings 
with no HVAC is higher than in the other studies, which can be attributed to the higher sensitivity of such buildings to the climate when compared to buildings with HVAC. This comparison suggests that the degree-days method applied to climatic zoning works better with conditioned buildings than natural ventilated ones. Moreover, it is noticeable that the same climatic zoning methodology can deliver substantially different results depending on the building stock of the area under evaluation. Hence, there are no good or bad methodologies per se and performance-based validation should be used to check the quality of every climatic zoning, as building stock varies from place to place.

It is important to highlight that maps illustrating misclassified areas in this study are just a way of graphically representing the magnitude and distribution of the mismatch between climatic zoning and performance. These maps, however, do not and should not be understood as a solution to the problem of defining climatic zones. Further research is needed to define the appropriate ways to leverage the information in such maps in the zoning process, addressing questions such as the ranges of performance variations in the zones, zoning resolution (number of zones), definition of zone boundaries under uncertainty and its implications in policy-making, as well as continuity constraints in zoning and the implications of all these decisions in building energy codes.

\section{CONCLUSION AND POLICY IMPLICATIONS}

A performance-based validation method was applied to the latest version of the climatic zoning incorporated in the ASHRAE Standards, using 52 archetype buildings complying with building energy requirements of Zones $1 \mathrm{~A}$ to 4A based on the ASHRAE Standard 90.1-2013. The archetypes represent multi-family buildings, hotels, offices, restaurants, retails, and schools. The study covered the range of weather conditions within the States of Florida, Georgia and Tennessee. This area covers around $433365 \mathrm{~km}^{2}$ and hosts almost 32 million people.

The method applied was capable of quantifying the level of agreement between climatic zoning and building performance in terms of cooling and heating energy demand of buildings. Results suggest that even though there is a strong correlation between degree-days and the energy consumption of the models under analysis, there are important overlaps of performance between zones. These overlaps have direct impact on the building energy efficiency policies of a given location, which may not be the most adequate for its climate. In this case study, misclassification particularly occurs at boundaries between Zone3A and Zone 4A, where the change in building energy requirements is more important when compared to the remaining zones. Such differences have significant cost implications and become more important when large urban agglomerations are located in potentially misclassified areas 
Results also indicate the challenges of designing a set of climatic zones to address multiple building types, as each building type shows a particular sensitivity to climate. The same zoning that has a low amount of misclassified areas for one archetype may have high occurrence for another. Policy makers can use this information to weight the importance of each archetype in the definition of zoning boundaries and target policies to particular building type. The analysis and implications of the misclassification calculated for each building type could be further analysed based on different sources of Geospatial data according to the interest of policy makers.

In quantitative terms, the Mean Percentage of Misclassified Areas of this case study suggest that 1 out of 10 areas $(10 \%$ of the territory analysed) could have been misclassified in the new climatic zoning of the ASHRAE Standard 169-2013 considering buildings of the U.S. Department of Energy complying with the Standard 90.12013. This is a significant level of mismatch, but it shows improvements in the zoning quality when compared to the previous version of the ASHRAE climatic zoning (MPMA of $\sim 15 \%$ as reported in a previous study). These improvements reflect the importance of considering the effect of global warming in building energy policies.

Despite such developments, results of this research indicate the need for more studies to support further improvements in the accuracy of climatic zones based on degree-days methods in the North American context, considering that millions of people live in areas that may have been misclassified. Misclassification could have a significant impact on building industry, energy performance of the building stock and building energy policies. In addition to this, it is important to highlight that the ASHRAE climatic zones affect more than just building construction regulations. There is a number of programs, standards, and policies to promote green building and beyond code initiatives relying in such climatic zones. Examples of these programs and standards are the Leadership in Energy and Environmental Design (LEED) and the Standard 189.1 for the Design of HighPerformance Green Buildings.

Findings of this work could have a profound impact on building energy regulations in many other countries adopting the degree-days approach, considering that the degree-days method is more suitable to areas where HVAC is widespread in the building stock than areas primarily dominated by naturally ventilated buildings. These findings are particularly relevant for low income and middle income countries in hot climates. In such countries, energy conservation strategies derived from climatic zoning could have a substantial impact on the future of global energy use, as the population and energy demand grows faster in this region than anywhere else in the world. Many studies have highlighted the rapid penetration of air conditioning in such countries. This is a situation that can be seen as a business opportunity for manufacturers and suppliers of high-efficiency air conditioning systems; however, if we consider current trends, meeting the increased demand for electricity could 
be an enormous challenge in the near future. In that sense, the use of performance-based validation is recommended for every climatic zoning, as building stocks and performance metrics vary from country to country. 


\section{ACKNOWLEDGMENT}

This study was supported by the São Paulo State Research Foundation (FAPESP) [grant number 2018/00976-1 and 2017/14617-0] and the Brazilian National Council for Scientific and Technological development (CNPq) [grant number 311641/2013-0].

\section{REFERENCES}

ANSI/ASHRAE/IES, 2013. ANSI/ASHRAE/IES Standard, 90.1-2013. Energy Standard for buildings except low-rise residential buildings.

ANSI/ASHRAE/IESNA, 2016. ANSI/ASHRAE/IES Standard 90.1-2016. Energy standard for buildings except low-rise residential buildings.

ANSI/ASHRAE, 2013a. Standard 169-2013, Climatic Data for Building Design Standards.

ANSI/ASHRAE, 2013b. ANSI/ASHRAE Standard 169-2013, Climatic Data for Building Design Standards 8400,104 .

Athalye, R., Taylor, T., Liu, B., 2016. Impact of ASHRAE Standard 169-2013 on building energy codes and energy efficiency. ASHRAE Trans. 431-438.

Attia, S., Lacombe, T., Rakotondramiarana, H.T., Garde, F., Roshan, G.R., 2019. Analysis tool for bioclimatic design strategies in hot humid climates. Sustain. Cities Soc. 45, 8-24. https://doi.org/10.1016/j.scs.2018.11.025

Bavaresco, M.V., Mazzaferro, L., Melo, A.P., Lamberts, R., 2017. Classificação de climas brasileiros empregada na atualização dos Regulamentos Técnicos da Qualidade para o Nível de Eficiência Energética de Edificações.

Beck, H.E., Zimmermann, N.E., McVicar, T.R., Vergopolan, N., Berg, A., Wood, E.F., 2018. Present and future Köppen-Geiger climate classification maps at 1-km resolution. Sci. Data 5, 180214. https://doi.org/10.1038/sdata.2018.214

Briggs, R.S., Lucas, R.G., Taylor, Z.T., 2003. Climate classification for building energy codes and standards, in: ASHRAE Transactions. ASHRAE, Atlanta, USA.

Burleyson, C.D., Voisin, N., Taylor, Z.T., Xie, Y., Kraucunas, I., 2017. Simulated building energy demand biases resulting from the use of representative weather stations. Appl. Energy 209, 516-528.

California Energy Commission, 2017. California Energy Maps [WWW Document]. Webpage. URL http://www.energy.ca.gov/maps/renewable/building_climate_zones.html (accessed 4.1.18).

California Energy Commission, 2013. Building energy efficiency standards for residential and nonresidential 
buildings.

Chen, Y., Tong, Z., Malkawi, A., 2017. Investigating natural ventilation potentials across the globe: Regional and climatic variations. Build. Environ. 122, 386-396. https://doi.org/10.1016/j.buildenv.2017.06.026

CIBSE, 2006. Degree-days: theory and application. CIBSE, London.

Clarke, J., Mcghee, R., Svehla, K., 2015. Opportunity mapping for urban renewables generation Stage 1 : Photovoltaics Final report 44.

Clarke, J.A., 2018. The role of building operational emulation in realizing a resilient built environment. Archit. Sci. Rev. 61, 358-361.

Clarke, J.A., 2001. Energy simulation in building design, Energy Simulation in Building Design. Taylor \& Francis group.

Clarke, J.A., Hensen, J.L.M., 2015. Integrated building performance simulation: Progress, prospects and requirements. Build. Environ. 91, 294-306.

Costanzo, E., Martino, A., Varalda, G.M., Antinucci, M., Federici, A., 2016. EPBD implementation in Italy.

Crawley, Drury Browne, 2008. Building performance simulation: a tool for policymaking. University of Strathclyde.

Crawley, Drury B., 2008. Estimating the impacts of climate change and urbanization on building performance. J. Build. Perform. Simul. 1, 91-115. https://doi.org/10.1080/19401490802182079

Dascalaki, E.G., Balaras, C.A., Gaglia, A.G., Droutsa, K.G., Kontoyiannidis, S., 2012. Energy performance of buildings_EPBD in Greece. Energy Policy 45, 469-477. https://doi.org/10.1016/j.enpol.2012.02.058

de Dear, R.J., Brager, G.S., 2002. Thermal comfort in naturally ventilated buildings: revisions to ASHRAE Standard 55. Energy Build. 34, 549-561. https://doi.org/10.1016/S0378-7788(02)00005-1

Deru, M., Field, K., Studer, D., Benne, K., Griffith, B., Torcellini, P., Liu, B., Halverson, M., Winiarski, D., Rosenberg, M., Deru, M., Field, K., Studer, D., 2011. U. S. Department of Energy Commercial Reference Building Models of the National Building Stock.

DOE, 2018. Weather Data [WWW Document]. URL https://energyplus.net/weather (accessed 12.10.17).

DOE, 2017. EnergyPlus Version 8.6.0 [WWW Document]. URL https://energyplus.net/

DOE, 2016. Commercial Prototype Building Models [WWW Document]. URL https://www.energycodes.gov/development/commercial/prototype_models (accessed 5.5.18).

EIA, 2003. Commercial buildings energy consumption survey [WWW Document]. URL https://www.eia.gov/consumption/commercial/data/2012/ 
ESRI, 2018. ArcGIS Desktop: 10.6.

Fossati, M., Scalco, V.A., Linczuk, V.C.C., Lamberts, R., 2016. Building energy efficiency: An overview of the Brazilian residential labeling scheme. Renew. Sustain. Energy Rev. 65, 1216-1231. https://doi.org/10.1016/j.rser.2016.06.048

Geller, H., Harrington, P., Rosenfeld, A.H., Tanishima, S., Unander, F., 2006. Polices for increasing energy efficiency: Thirty years of experience in OECD countries. Energy Policy 34, 556-573.

Glazer, J., 2015. Final report ASHRAE 1651-RP Development of maximum technically achievable energy targets for commercial buildings. Illinois.

Goel, S., Rosenberg, M., Athalye, R., Xie, Y., 2014. Enhancements to ASHRAE Standard 90.1 Prototype Building Models. Pacific Northwest Natl. Lab.

Hensen, J.L.M. (Jan), 1999. Simulation of building energy and indoor environmental quality - Some weather data Issues, in: The International Workshop on Climate Data and Their Applications in Engineering. Prague, Czech Republic.

Hensen, J.L.M., Lamberts, R., 2019. Building Performance Simulation for Design and Operation, Spon Press. ed. Routledge, Second edition. | Abingdon, Oxon ; New York, NY : Routledge, 2019. https://doi.org/10.1201/9780429402296

Hogan, J., 2014. Changes in ASHRAE Standard 169 : Implications for Energy Codes and Standards, in: ASHRAE Transactions. pp. 1-7.

Hong, T., Li, C., Yan, D., 2015. Updates to the China Design Standard for Energy Efficiency in public buildings. Energy Policy 87, 187-198.

Hu, S., Yan, D., Cui, Y., Guo, S., 2016. Urban residential heating in hot summer and cold winter zones of China-Status, modeling, and scenarios to 2030. Energy Policy 92, 158-170.

Huang, B., Cova, T., Tsou, M.-H., 2017. Comprehensive Geographic Information Systems, Comprehensive Geographic Information Systems. Elsevier.

International Code Council, 2012. IECC-2012- International Energy Conservation Code. USA.

Italian Legislative Decree n. 192/05, 2005. Attuazione della direttiva 2002/91/CE relativa al rendimento energetico nell'edilizia. Italia.

Jain, A.K., 2010. Data clustering: 50 years beyond K-means. Pattern Recognit. Lett. 31, 651-666.

Jakubcionis, M., Carlsson, J., 2018. Estimation of European Union service sector space cooling potential. Energy Policy 113, 223-231. 
Jenkins, D.P., Ingram, V., Simpson, S.A., Patidar, S., 2013. Methods for assessing domestic overheating for future building regulation compliance. Energy Policy 56, 684-692. https://doi.org/10.1016/j.enpol.2013.01.030

Koenigsberger, O.H., Mahoney, C.T., Evans, M., 1971. Climate and house design. New York.

Koirala, B.S., Bohara, A.K., Berrens, R.P., 2014. Estimating the net implicit price of energy efficient building codes on U.S. households. Energy Policy 73, 667-675.

Kotireddy, R., Hoes, P.J., Hensen, J.L.M., 2018. A methodology for performance robustness assessment of lowenergy buildings using scenario analysis. Appl. Energy 212, 428-442. https://doi.org/10.1016/j.apenergy.2017.12.066

Lindberg, F., Grimmond, C.S.B., Gabey, A., Huang, B., Kent, C.W., Sun, T., Theeuwes, N.E., Järvi, L., Ward, H.C., Capel-Timms, I., Chang, Y., Jonsson, P., Krave, N., Liu, D., Meyer, D., Olofson, K.F.G., Tan, J., Wästberg, D., Xue, L., Zhang, Z., 2018. Urban Multi-scale Environmental Predictor (UMEP): An integrated tool for city-based climate services. Environ. Model. Softw. 99, 70-87.

Liu, F., Meyer, A.S., Hogan, J.F., 2010. Mainstreaming building energy efficiency codes in developing countries. Global experiences and lessons from early adopters. WB, Washington, D.C.

Lomas, K.J., Fiala, D., Cook, M.J., Cropper, P.C., 2004. Building bioclimatic charts for non-domestic buildings and passive downdraught evaporative cooling. Build. Environ. 39, 661-676.

M. Carpio, Jódar, J., Rodíguez, M.L., Zamorano, M., 2015. A proposed method based on approximation and interpolation for determining climatic zones and its effect on energy demand and $\mathrm{CO} 2$ emissions from buildings. Energy Build. 87, 253-264.

MathWorks, 2016. Matlab.

Nageler, P., Zahrer, G., Heimrath, R., Mach, T., Mauthner, F., Leusbrock, I., Schranzhofer, H., Hochenauer, C., 2017. Novel validated method for GIS based automated dynamic urban building energy simulations. Energy 139, 142-154. https://doi.org/10.1016/j.energy.2017.07.151

Perez, R., David, M., Hoff, T.E., Jamaly, M., Kivalov, S., Kleissl, J., Lauret, P., Perez, M., 2016. Spatial and Temporal Variability of Solar Energy. Found. Trends ${ }^{\circledR}$ Renew. Energy 1, 1-44.

Praene, J.P., Malet-damour, B., Radanielina, M.H., Rivière, G., 2019. GIS-based approach to identify climatic zoning : a hierarchical clustering on principal component analysis. Build. Environ. 106330. 
https://doi.org/10.1016/j.buildenv.2019.106330

Pusat, S., Ekmekci, I., 2016. A study on degree-day regions of Turkey. Energy Effic. 9, 525-532.

Rackes, A., Melo, A.P., Lamberts, R., 2016. Naturally comfortable and sustainable: Informed design guidance and performance labeling for passive commercial buildings in hot climates. Appl. Energy 174, 256-274.

Reinhart, C.F., Cerezo Davila, C., 2016. Urban building energy modeling - A review of a nascent field. Build. Environ. 97, 196-202.

Richman, R., Zirnhelt, H., Fix, S., 2014. Large-scale building simulation using cloud computing for estimating lifecycle energy consumption. Can. J. Civ. Eng. 41, 252-262. https://doi.org/10.1139/cjce-2013-0235

Roth, M., 2017. Updating the ASHRAE climate design date for 2017, in: ASHRAE Transactions. pp. 80-89.

Sailor, D.J., Vasireddy, C., 2006. Correcting aggregate energy consumption data to account for variability in local weather. Environ. Model. Softw. 21, 733-738.

Sánchez-Lozano, J.M., Teruel-Solano, J., Soto-Elvira, P.L., Socorro García-Cascales, M., 2013. Geographical Information Systems (GIS) and Multi-Criteria Decision Making (MCDM) methods for the evaluation of solar farms locations: Case study in south-eastern Spain. Renew. Sustain. Energy Rev. 24, 544-556.

Sisman, N., Kahya, E., Aras, N., Aras, H., 2007. Determination of optimum insulation thicknesses of the external walls and roof (ceiling) for Turkey’s different degree-day regions. Energy Policy 35, 5151-5155. https://doi.org/10.1016/j.enpol.2007.04.037

Sivak, M., 2009. Potential energy demand for cooling in the 50 largest metropolitan areas of the world: Implications for developing countries. Energy Policy 37, 1382-1384.

Taylor, J., Davies, M., Mavrogianni, a., Chalabi, Z., Biddulph, P., Oikonomou, E., Das, P., Jones, B., 2014. The relative importance of input weather data for indoor overheating risk assessment in dwellings. Build. Environ. 76, 81-91. https://doi.org/10.1016/j.buildenv.2014.03.010

Verichev, K., Carpio, M., 2019. Assessing the applicability of various climatic zoning methods for building construction : Case study from the extreme southern part of Chile. Build. Environ. 160, 106165. https://doi.org/10.1016/j.buildenv.2019.106165

Villareal, M.J.C., Moreira, J.M.L., 2016. Household consumption of electricity in Brazil between 1985 and 2013. Energy Policy 96, 251-259. https://doi.org/10.1016/j.enpol.2016.04.030

Visscher, H., Laubscher, J., Chan, E., Visscher, H., Laubscher, J., Chan, E., 2016. regulation and related polices Building governance and climate change : roles for regulation and related polices. Build. Res. Inf. 3218. https://doi.org/10.1080/09613218.2016.1182786 
Walsh, A., Cóstola, D., Labaki, L.C., 2018a. Performance-based validation of climatic zoning for building energy efficiency applications. Appl. Energy 212, 416-427.

Walsh, A., Cóstola, D., Labaki, L.C., 2018b. Validation of the degree-days method for climatic zoning-Initial results based on the Mean Percentage of Misclassified Areas, in: University of Strathclyde (Ed.), USIM 2018 - Urban Energy Simulation. Glasgow.

Walsh, A., Cóstola, D., Labaki, L.C., 2017a. Review of methods for climatic zoning for building energy efficiency programs. Build. Environ. 112, 337-350. https://doi.org/10.1016/j.buildenv.2016.11.046

Walsh, A., Cóstola, D., Labaki, L.C., 2017b. Comparison of three climatic zoning methodologies for building energy efficiency applications. Energy Build. 146, 111-121. https://doi.org/10.1016/j.enbuild.2017.04.044

Wang, H., Chen, Q., 2014. Impact of climate change heating and cooling energy use in buildings in the United States. Energy Build. 82, 428-436.

Wang, N., Makhmalbaf, A., Srivastava, V., Hathaway, J.E., 2017. Simulation-based coefficients for adjusting climate impact on energy consumption of commercial buildings. Build. Simul. 10, 309-322.

Ware, D.W., Bozorgchami, P., 2013. Energy efficiency comparison-California’s Building Energy Efficiency Standards and the IECC and ASHRAE standard 90.1. CEC.

Wu, J., Xu, Z., Jiang, F., 2019. Analysis and development trends of Chinese energy efficiency standards for room air conditioners. Energy Policy 125, 368-383. https://doi.org/10.1016/j.enpol.2018.10.038

\section{FIGURES}


a)

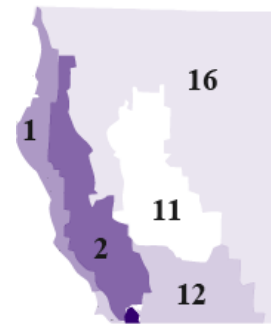

California Energy Commission

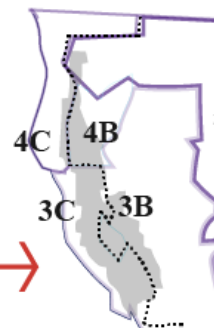

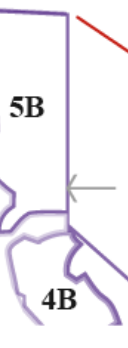

IECC/ASHRAE 90.1-2013

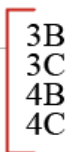

b)

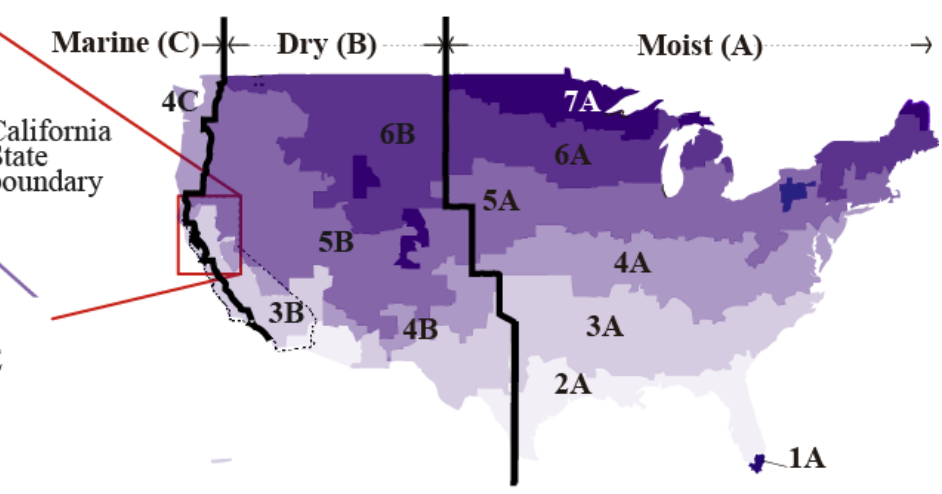

Numbers Indicate climatic zones according to Cooling and Heating degree days and letters (A, B and C) indicate the level of humidity according to ASHRAE 90.1-2013.

Figure 1:a) Different requirements for the same region of California (Walsh et al., 2017; Ware and

Bozorgchami, 2013) and b) Original ASHRAE climatic zones (Briggs et al., 2003).

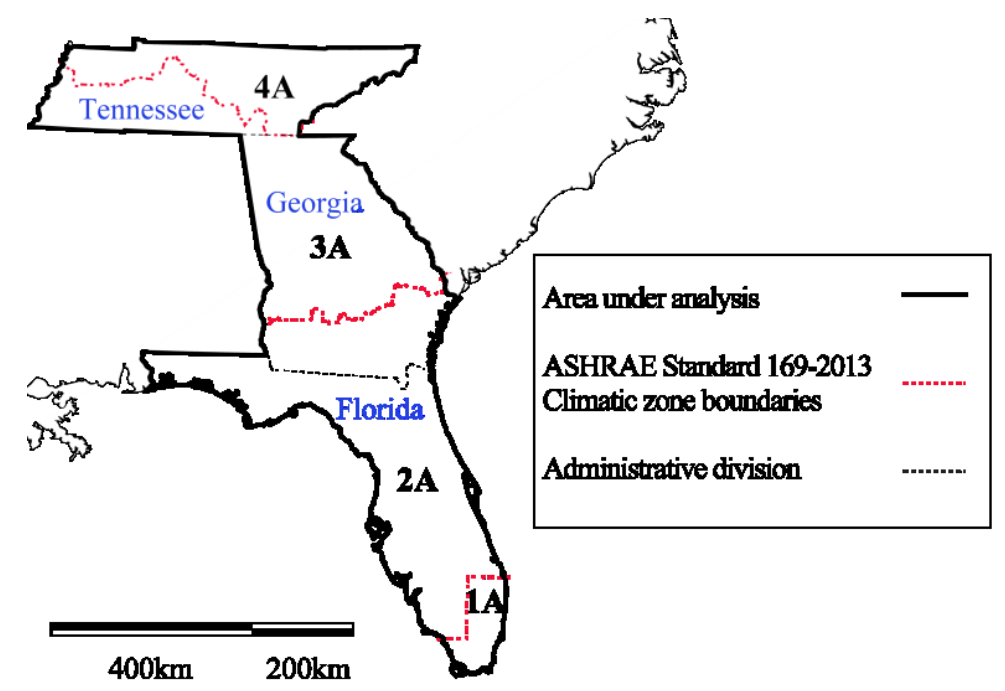

Figure 2 Area under analysis 


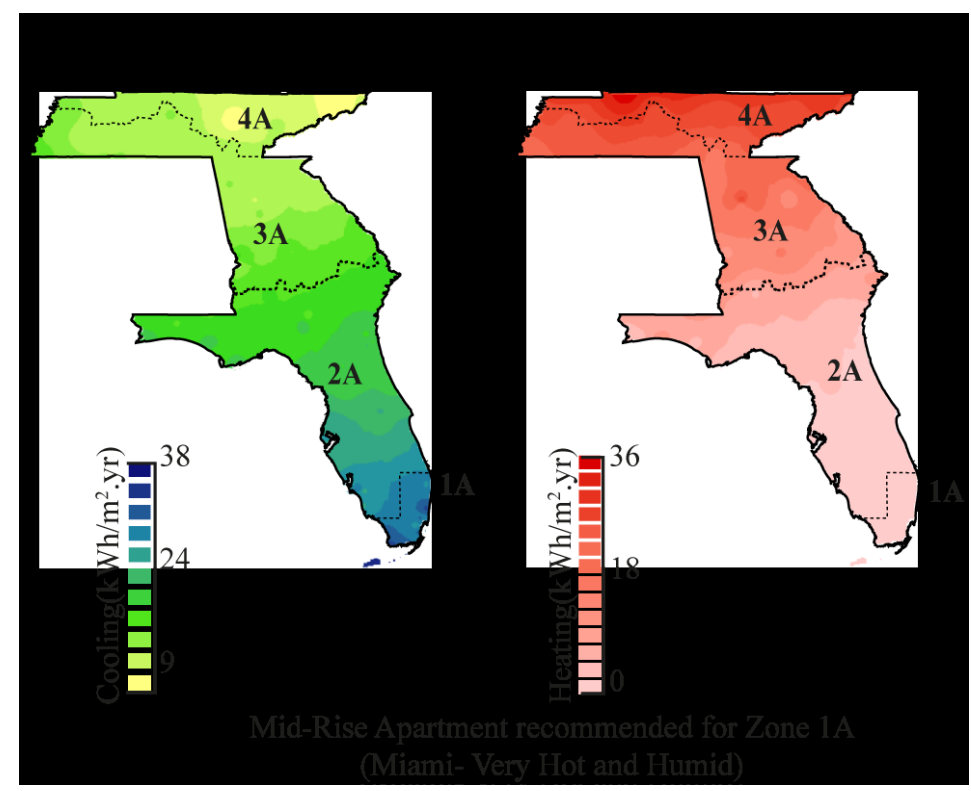

Figure 3 Performance-based maps of a) Cooling and b) Heating energy demand of mid-rise apartments complying with Zone 1A requirements based on the ASHRAE Standard 90.1-2013.

a)

c)

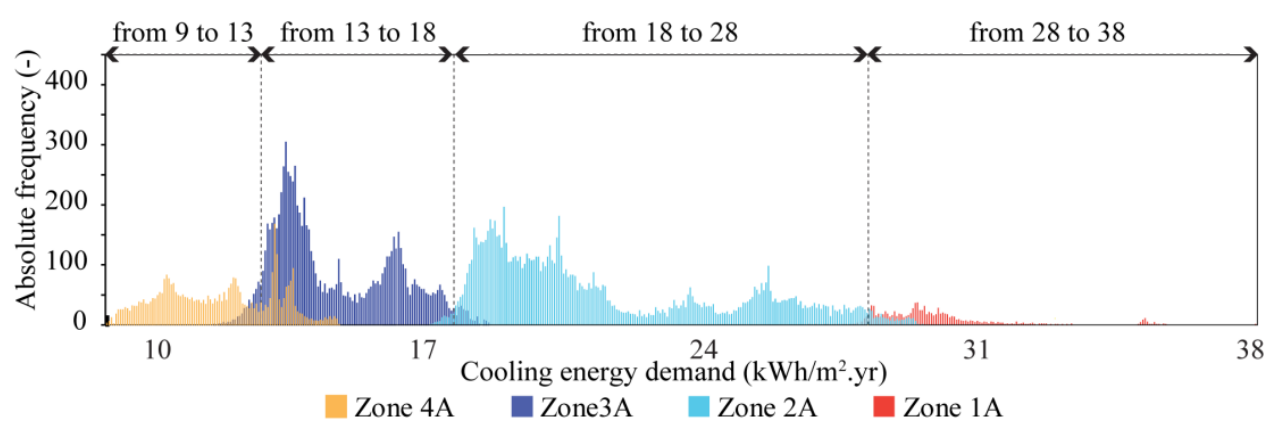

b)
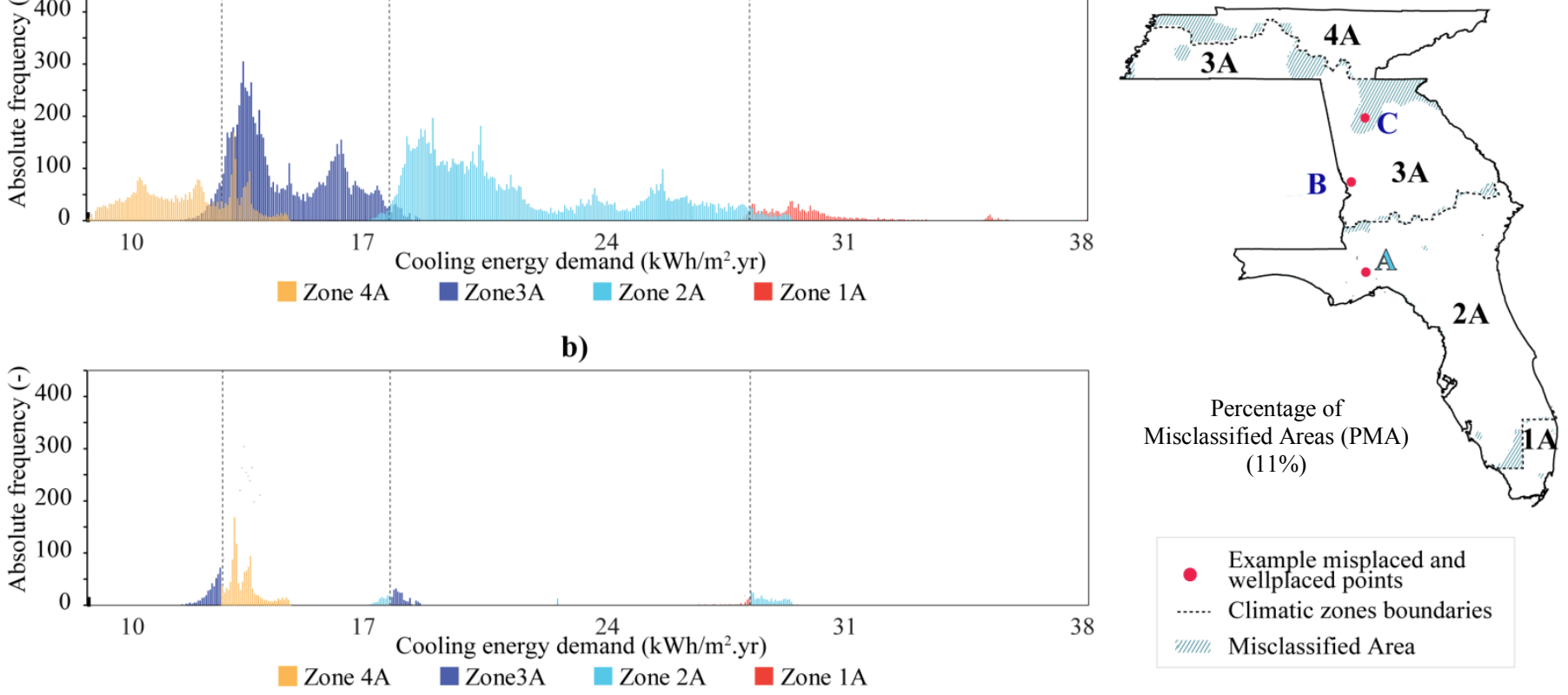

- Example misplaced and

- wellplaced points

-.... Climatic zones boundaries

(yוll, Misclassified Area

Figure 4 a) Histograms of cooling energy demand for Mid-Rise apartments complying with Zone $1 \mathrm{~A}$ requirements of the Standard 90.1-2013 b) frequency bars related to misclassified points and c) misclassified areas. 


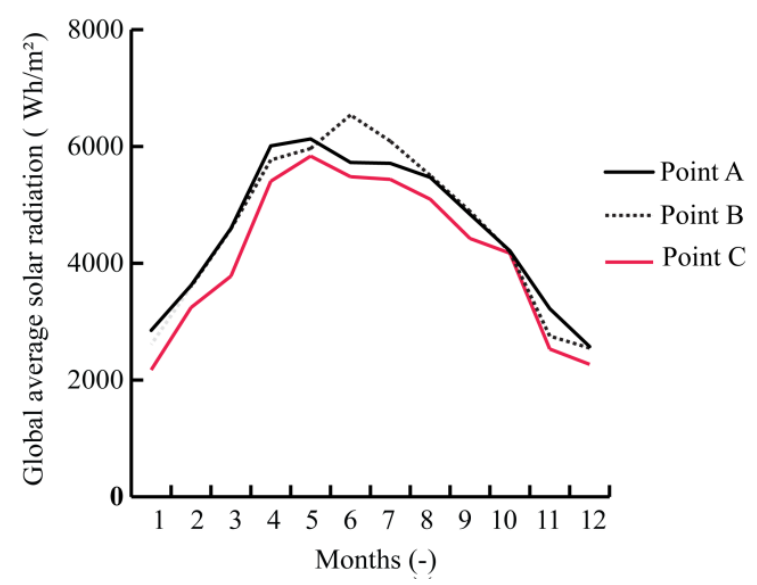

Figure 5 Solar radiation of three locations belonging to different zones according the ASHRAE Standard 90.1-2013.

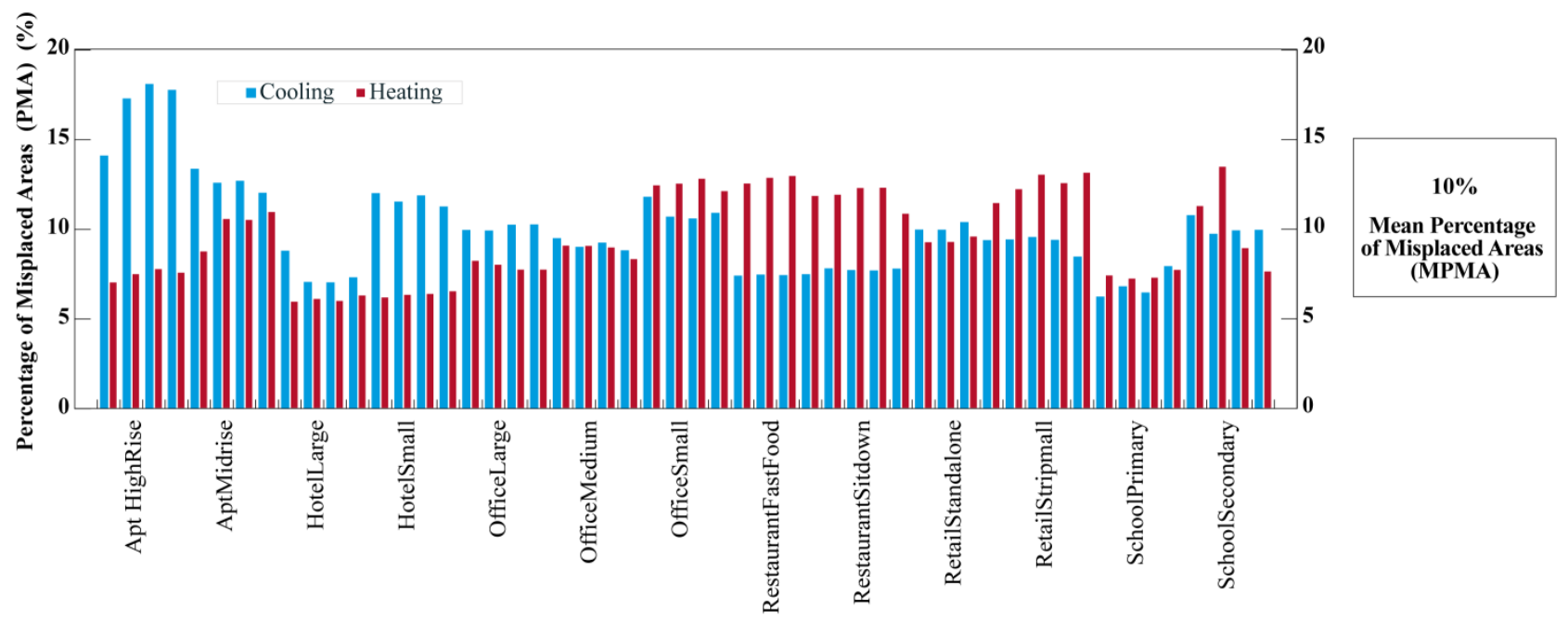

Figure 6 PMA based on cooling and heating energy demand for each archetype and MPMA results 


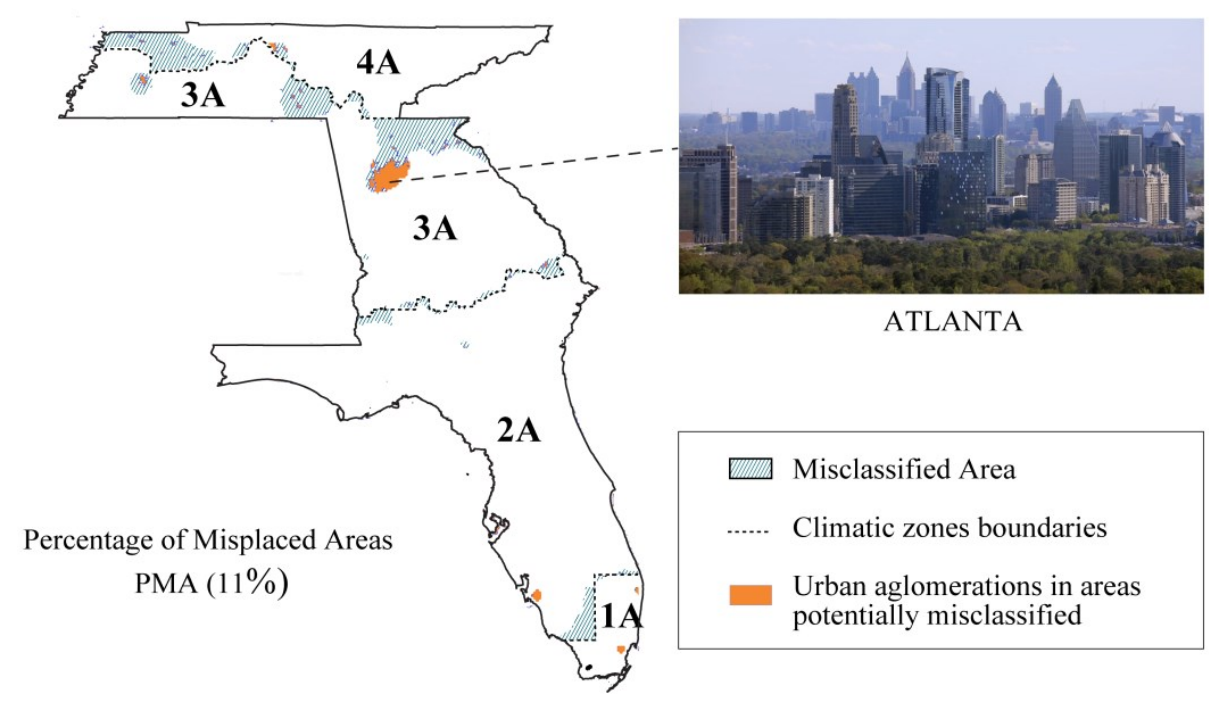

Figure 7 Potential misclassified areas for mid-rise apartments archetype (suited for zone 3A) according to the ASHRAE 169-2013 climatic zoning

a)
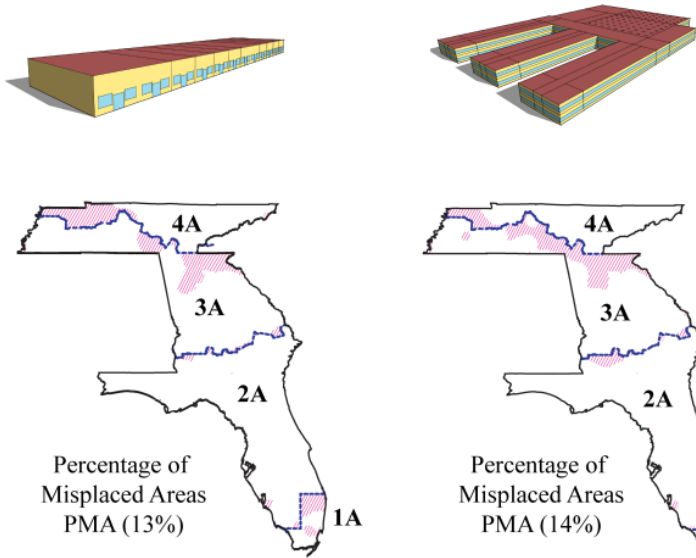

Strip mall

Recomended for Zone $2 \mathrm{~A}$

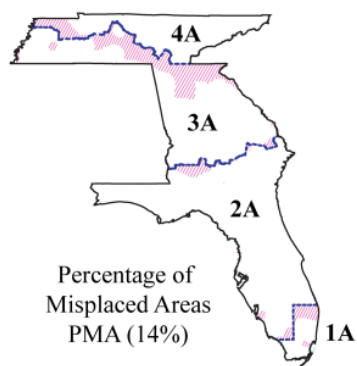

School Secondary

Recomended for Zone $2 \mathrm{~A}$

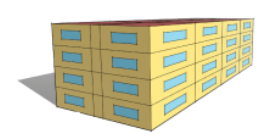

b)

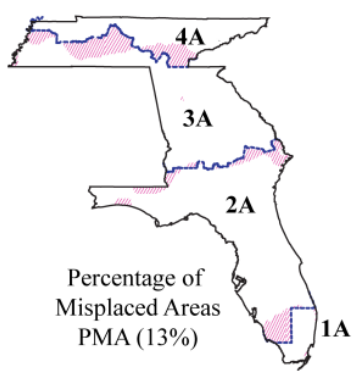

Mid-Rise Apartment

Recomended for Zone $4 \mathrm{~A}$
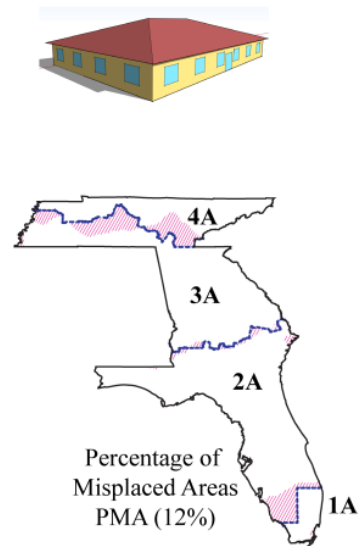

Office Small

Recomended for Zone4A

----.- Climatic zones boundaries

$\square$ Misclassified Area

Figure 8 Example of misclassified areas based on a) cooling and b) heating of different building types 


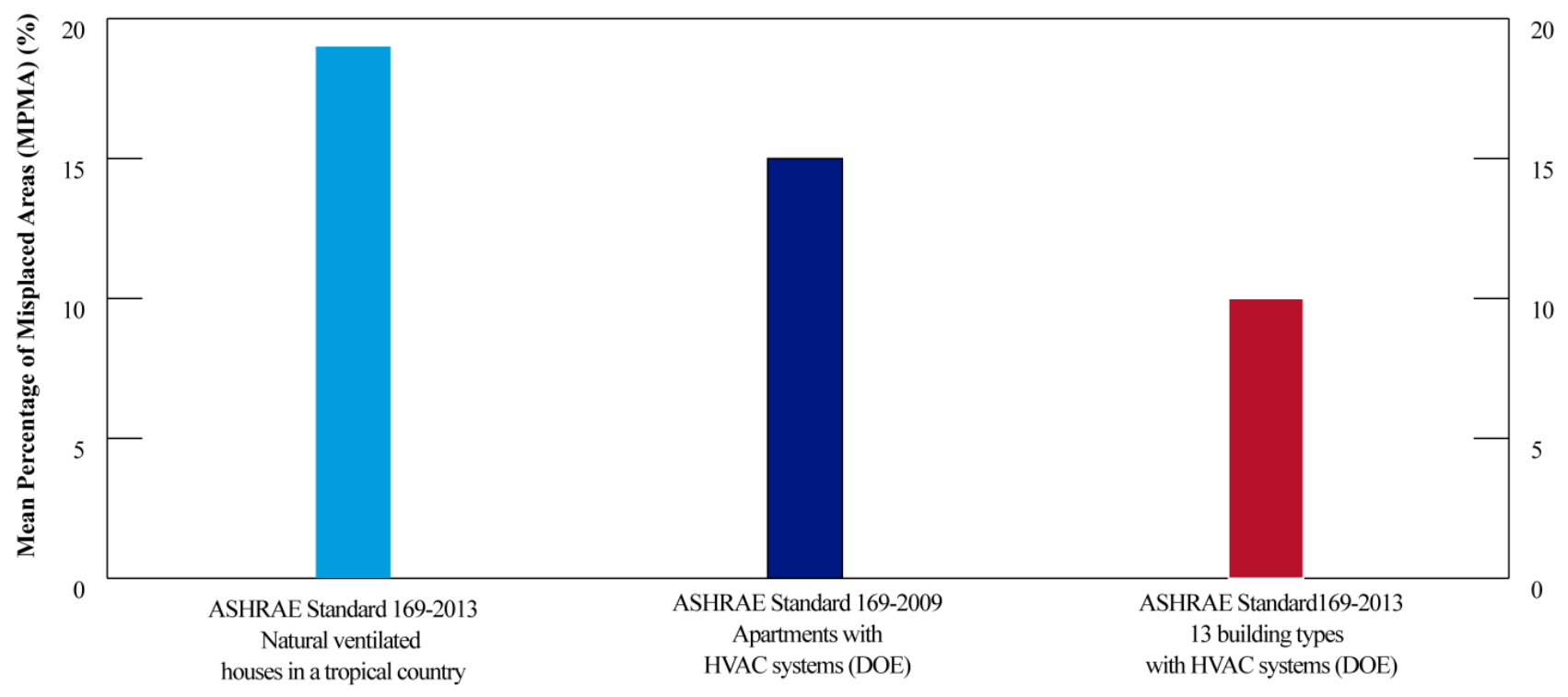

Figure 9 Comparison of MPMA with previous (Walsh et al., 2018a, 2018b). 